PHYSICAL REVIEW FLUIDS 1, 050504 (2016)

\title{
Tightrope dancer bubbles
}

\author{
A. Duchesne, ${ }^{*}$ C. Dubois, and H. Caps ${ }^{\dagger}$ \\ GRASP, Department of Physics, UR-CESAM, University of Liège, B-4000 Liège, Belgium
}

(Received 7 July 2016; published 12 September 2016)

\begin{abstract}
This paper is associated with a video winner of a 2015 APS/DFD Milton van Dyke Award for work presented at the DFD Gallery of Fluid Motion. The original video is available from the Gallery of Fluid Motion, http://dx.doi.org/10.1103/APS.DFD.2015.GFM.V0013
\end{abstract}

DOI: 10.1103/PhysRevFluids.1.050504

When a metallic wire is heated up to the boiling point in a subcooled liquid bath some vapor bubbles nucleate on its surface. In the literature, it is admitted that these bubbles generated from active nucleate sites grow up and depart from the heating surface due to buoyancy and inertia. Wang et al. [1] observed an alternative situation: In water or alcohol subcooled baths, bubbles can slide along a horizontal heated platinum thin wire. They also addressed other aspects of the problem such as the interactions between bubbles (bouncing or fusion) [2].

We performed experiments using a 5-cm-long horizontal constantan wire (diameter $\phi \in$ $[0.1 ; 1] \mathrm{mm})$ in a $1.5-\mathrm{cS}$ silicone oil subcooled bath. This is a total wetting situation. The resistive wire is heated up through Joule's effect with a current setting up to $64 \mathrm{~A}$. The injected power $P$ can thus reach $200 \mathrm{~W}$.

For $P=10 \mathrm{~W}$ and $\phi=0.2 \mathrm{~mm}$, as bubbles nucleate on the wire surface, they spontaneously move along it without preferential sense. They exhibit velocities up to $100 \mathrm{~mm} / \mathrm{s}$. Bubbles may appear and move on top of or beneath the wire. One can notice that the top position is more stable due to Archimede's force. In Fig. 1(a), a typical view of such a bubble and its thermal plume is presented. If two bubbles come into contact they can bounce or fuse [see Fig. 1(b)].

Keeping $\phi$ fixed to $0.2 \mathrm{~mm}$ and increasing $P$ up to $17.5 \mathrm{~W}$, one can observe a new regime: Motionless clusters composed of a few big bubbles $(\sim 0.5 \mathrm{~mm})$ steadily remain on the wire [see Fig. 1(c)]. Small bubbles continue to circulate between these clusters. If we further increase the heating power $P$, clusters elongate along the whole wire up to cover it as a single motionless cluster [see Fig. 1(d)]. If we continue to increase the injected heat ( $\phi$ staying fixed to $0.2 \mathrm{~mm}$ ), we observe that this unique cluster dislocates into smaller clusters until this regime ends and the system returns to the situation previously described where isolated bubbles move freely.

Increasing $P$ up to $30 \mathrm{~W}$, a vapor film totally isolates the wire from the liquid bath [see Fig. 2(a)]. This phenomenon is called film boiling. Because of Rayleigh-Taylor instability, this vapor film is destabilized following a well defined wavelength [3]. If we now change the wire diameter in this regime, the destabilization pattern will be modified: For small diameters one can observe pearls [see Fig. 2(a)], while for large ones we observe medusa [see Fig. 2(b)].

We believe that there is a common mechanism that could explain why the bubbles do not leave the wire and from which the horizontal propulsion mechanism arises: thermal Marangoni flows. Temperature differences appear between the top and the bottom of the bubble (the wire heats the bottom but the top is still close to the subcooled bath temperature) and also between the front and

\footnotetext{
*alexis.duchesne@ulg.ac.be
}

†herve.caps@ulg.ac.be

Published by the American Physical Society under the terms of the Creative Commons Attribution 3.0 License. Further distribution of this work must maintain attribution to the author(s) and the published article's title, journal citation, and DOI. 

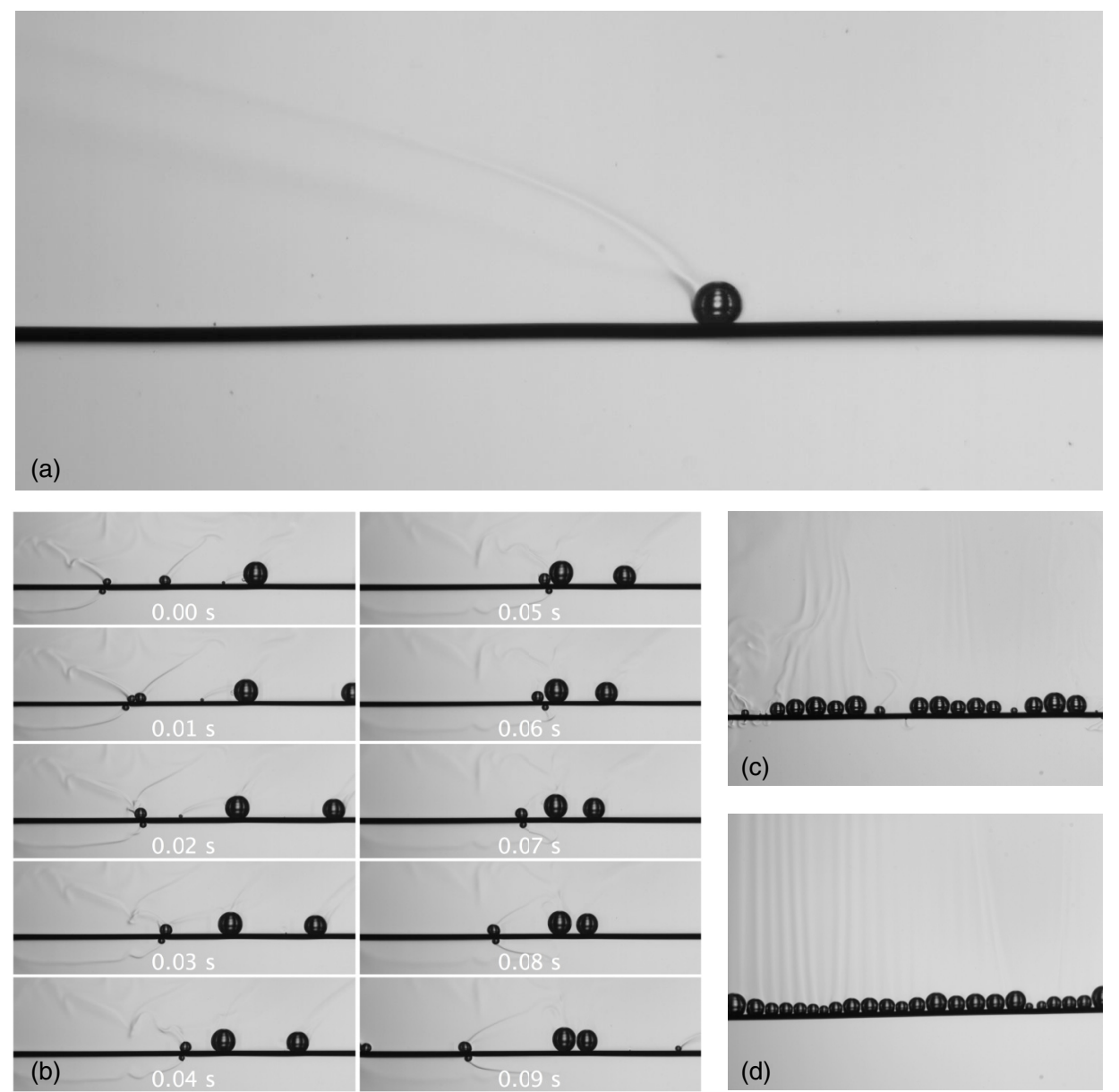

FIG. 1. (a) Image of a bubble moving on a hot wire for $\phi=0.2 \mathrm{~mm}$ and $P=10 \mathrm{~W}$. One can notice the inclined thermal plume as a signature of the bubble motion. The bubble velocity is $v \sim 60 \mathrm{~mm} / \mathrm{s}$. (b) Motion of some bubbles on a heated wire for $\phi=0.2 \mathrm{~mm}$ and $P=15 \mathrm{~W}$. Images are separated by $0.01 \mathrm{~s}$. When two bubbles come into contact they can bounce (between 0.04 and $0.07 \mathrm{~s}$ ) or fuse (between 0.00 and $0.02 \mathrm{~s}$ ). (c) Cluster regime, with $\phi=0.2 \mathrm{~mm}$ and $P=17.5 \mathrm{~W}$. (d) The wire is covered by a single (almost) motionless cluster, with $\phi=0.2 \mathrm{~mm}$ and $P=20 \mathrm{~W}$. DOI: http://dx.doi.org/10.1103/APS.DFD.2015.GFM.V0013

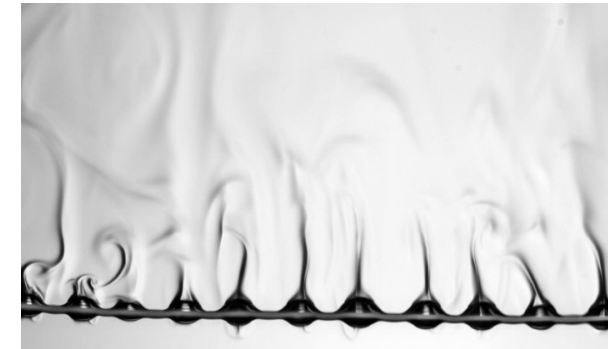

(a)

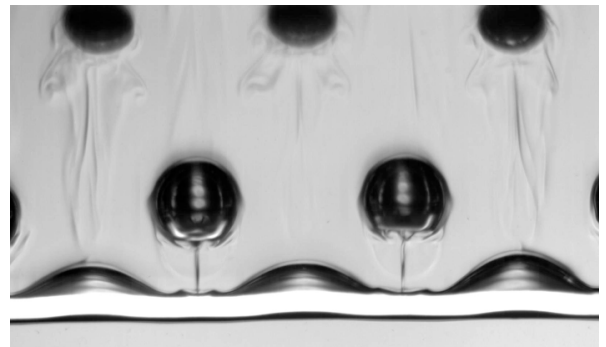

(b)

FIG. 2. Film boiling patterns: (a) pearl regime, with $\phi=0.2 \mathrm{~mm}$ and $P=45 \mathrm{~W}$, and (b) medusa regime, with $\phi=0.6 \mathrm{~mm}$ and $P=90 \mathrm{~W}$. DOI: http://dx.doi.org/10.1103/APS.DFD.2015.GFM.V0013 


\section{TIGHTROPE DANCER BUBBLES}

the rear of the bubble [4] (the motion of the bubble creates a mixing zone at the bubble rear inducing a cooler zone). Thermal Marangoni flows, occurring for a bubble in a thermal gradient, attract the bubble to the hottest temperature points [5]. This mechanism can thus explain our observations.

This project was financially supported by an ARC SuperCool contract of the University of Liège. M. Mélard and S. Rondia are particularly thanked for technical support.

[1] H. Wang, X. F. Peng, B. X. Wang, and D. J. Lee, Bubble sweeping and jet flows during nucleate boiling of subcooled liquids, Int. J. Heat Mass Transfer 46, 863 (2003).

[2] J. F. Lu and X. F. Peng, Bubble separation and collision on thin wires during subcooled boiling, Int. J. Heat Mass Transfer 48, 4726 (2005).

[3] J. H. Lienhard and P. T. Y. Wong, The dominant unstable wavelength and minimum heat flux during film boiling on a horizontal cylinder, J. Heat Transfer 86, 220 (1964).

[4] D. M. Christopher, H. Wang, and X. Peng, Dynamics of bubble motion and bubble top jet flows from moving vapor bubbles on microwires, J. Heat Transfer 127, 1260 (2005).

[5] N. O. Young, J. S. Goldstein, and M. J. Block, The motion of bubbles in a vertical temperature gradient, J. Fluid Mech. 6, 350 (1959). 